\title{
Bromine pretreated chitosan for adsorption of lead (II) from water
}

\author{
RAJENDRA DONGRE*, MINAKSHI THAKUR ${ }^{\dagger}$, DINESH GHUGAL and JOSTNA MESHRAM \\ P. G.T.D. of Chemistry, R. T. M. Nagpur University, Nagpur 440 033, India \\ ${ }^{\dagger}$ Department of Biotechnology, Madhav Institute of Technology and Science, Gwalior 474 005, India
}

MS received 20 September 2011; revised 6 November 2011

\begin{abstract}
Pollution by heavy metals like lead (II) is responsible for health hazards and environmental degradation. Adsorption is a prevalent method applied for removal of heavy metal pollutants from water. This study explored adsorption performances of $30 \%$ bromine pretreated chitosan for lead (II) abatement from water. Bromine pretreatment alters porosity and specific surface area of chitosan by means of physicochemical interaction with cationic sites of chitosan skeleton, besides imparting anionic alteration at amino linkages of chitosan, to remove lead (II) by chemical interactions on superfluous active sites as characterized by FTIR, SEM, DTA and elemental analysis. Lead adsorptions were studied in batch mode by varying parameters viz. $\mathbf{p H}$, bromine loading, sorbent dosage, initial lead concentration, contact time and temperature. The adsorption equilibrium data was well fitted to Freundlich isotherm and maximum sorption capacity of $30 \%$ bromine pretreated chitosan sorbent was $1.755 \mathrm{~g} / \mathrm{kg} \mathrm{with} 85$ $\mathbf{9 0 \%}$ lead removal efficiency. Though cost and applicability of sorbent is unproven, yet contrast to raw chitosan derivatives, activated carbons and some resins, $30 \%$ bromine pretreated chitosan endow benign and efficient lead abatement technique.
\end{abstract}

Keywords. Lead; $30 \%$ bromine pretreated chitosan; water; adsorption; langmuir; Freundlich.

\section{Introduction}

Many toxic heavy metals like lead, copper, zinc, mercury, chromium, arsenic and cadmium etc are either contaminated as natural constituents in earth crust (sediments deposit as metal salts) or enter owing to urbanization and a high degree of industrialization such as metal plating factories, mining operations and tanneries which substantially enhance ecological degradation (Das et al 2008). Their intrusion in water also leads to severe detrimental effects on human life and environment. Therefore, to remove such pollutants from water with plausible choice of treatments becomes a challenge to cleaner, friendlier and safer environment.

Lead (plumbum) is a shiny chrome white luster heavy element with soft, malleable poor metallic character soon turning to grayish on exposure to air. Nevertheless, lead (II) materials are used in building construction, batteries, bullets shots, weights, as part of solders, pewter's, fusible alloys, radiation lead shields as well as utilized mainly in metal manufacturing, mining, extractive metallurgical, electroplating and pigment (Londrigan et al 1990). Aquatic pollution of lead (II) poses serious environmental problem, due to toxicity and accumulation tendency through food chains (ATSDR 2007). Amid metal pollution cycle being most heavy, this lead (II) is a highly cumulative poison seldom recovering from the environment, so must be priory detained from entering into ecology (Goyer 1993). Lead at certain exposure is poisonous to human and animals due to damaging nervous

\footnotetext{
*Author for correspondence (rsdongre@ hotmail.com)
}

system and causing brain disorders or showed neurological symptoms like pain, muscle weakness, paraesthesia, as well as rare encephalitis. Other common symptoms in lead poisoning includes gastrointestinal harms, like constipation, diarrhea, poor appetite, weight loss, abdominal pain, nausea and vomiting (Pearce 2007). More acute lead absorption may cause shocks because water loss from gastrointestinal tract governs fluid control in circulatory system. Further lead (II) damages kidney and causes decreased urine output (Brunton et al 2007). Lead intrusion in human daily needs is ubiquitous and many people have some measurable blood lead level (Hu et al 2007; Karri et al 2008). Since 1970, regulatory norms in developed countries control lead content in products which greatly reduced its exposure to habitants; still in many developing countries, lead utility in products is non-regulated (Pokras and Kneeland 2008).

Numerous methods employed to remove lead from water such as chemical precipitation, sludge separation, chemical oxidation or reduction, ion exchange, reverse osmosis, membrane separation, electrochemical treatment and evaporation (Rusten et al 1997; Bailey et al 1999; Gogate and Pandit 2004; Cochrane et al 2006; Igwe and Abia 2006). However, certain techniques are expensive or possess some disadvantages like fewer lead removals, poor selectivity, more load of toxic solid waste/sludge as well as high cost and energy consumption. Nevertheless, adsorption process is found to be effective and economic for a wide variety of water pollutant sorption (Gogate and Pandit 2004). The activated carbon is most extensively used for lead removal, which is quite expensive and less effective on large scale (Babel and Kurniavan 
2003; Nadeem et al 2006). Adsorption by using biosorbents has been an economically feasible bioremediation alternative for lead removal as it offers the advantages of low operating cost, minimizing secondary pollution and high efficiency in wastes. The non-living biomass in biosorption is more practicably used and advantageous over living biomass cells as latter requires the addition of fermentation media which increase the biological oxygen demand or chemical oxygen demand of water. Besides, non-living biomass is unaffected by the toxicity of lead ions and they can be subjected to different chemical and physical treatment techniques to enhance their performance. In the recent past, considerable attention has been paid to natural biomaterials as alternative sorbent to reduce cost of adsorption systems (Quin et al 2008; Bulgariu et al 2009a). Hence, lead pollution from water was mitigated by assorted low-cost adsorbents like peat (Ho et al 1999; Bulgariu et al 2009b), lignin (Ucun et al 2003; Guo et al 2008) and fungi (Horsfall and Spiff 2005). Synthetic resins also showed high lead selectivity with excellent performance for lead removal; yet relatively very costly as compared to ion exchangers (Kuribayashi et al 1988; Abo-Farha et al 2009; Badawy et al 2009). Many such adsorbents either owe less adsorption capacity or technically non-feasible at field scale, besides the adsorption success hinges on developing environmentally benign, viably efficient and technically feasible sorbents. Consequently, selection of adsorbent critically focused on potential adsorption capacity, benign features and cost factors.

Chitosan is the most abundant polymer after cellulose and a hydrophilic natural polymer obtained by alkaline deacetylation of chitin as extracted from shrimp and crabshells (Arrascue et al 2003). Chitosan/chitin are excellent biosorbent due to unique structure, distinctive properties, safety and biodegradability, as a result frequently used for mitigation of toxic and strategic metals like mercury, cadmium, uranium, vanadium, platinum, gold, palladium and molybdenum (Milot et al 1998; Vieira and Beppu 2006; Fujiwara et al 2007; Sankararamakrishnan et al 2007; Wang 2008; Wang et al 2011). The surface modification of chitin/chitosan has become a popular method adopted to derive anticipated adsorbents characteristics for practical applications so far (Makkuni et al 2005; Nan et al 2005). N-atom/amino linkages of chitosan skeleton can be modified easily, so as to contribute towards chemical interactions with metal cations (Vieira and Beppu 2006). Chitosan derivatives are capable of adsorbing metal ions through many interactions like chemical/chelation, electrostatic and ion-exchange besides depending on metal chemistry and $\mathrm{pH}$ of medium (Dzul Erosa et al 2001; $\mathrm{Ng}$ et al 2003). Literature revealed chitosan's adsorption capacities for hydrochloric acid, sulfuric acid, nitric acid and iodine/bromide in aqueous conditions (Zhang et al 2009). Hence, chitosan was intentionally pretreated with $30 \%$ bromine $(\mathrm{KBr})$ to investigate optimum conditions for lead (II) adsorption under operating parameters like temperature, $\mathrm{pH}$ and initial lead concentration. Although cost and applicability of bromine pretreated chitosan is unproven, yet compared to traditional activated granular carbons and some resins, it endows benign and efficient adsorption technique for mitigating lead pollution from water without affecting its quality.

\section{Experimental}

\subsection{Materials}

The coarse grains chitin was purchased from M/s B.R. Corporation, Mumbai. Chitosan were obtained by about $80 \%$ deacetylation of chitin by treatment with $10 \mathrm{~N} \mathrm{NaOH}$ solution. Analytical grade potassium bromide $(\mathrm{KBr})$, nitric acid and anhydrous ethanol were used. And all the solutions were made with deionized (DI) water.

\subsection{Synthesis of samples}

About $3 \mathrm{~g}$ of chitosan, $30 \mathrm{~mL}$ of deionized water and $10 \mathrm{~mL}$ of anhydrous ethanol were taken in a $50 \mathrm{~mL}$ bottle and vigorously stirred for $1 \mathrm{~h}$, followed by addition of $1 \mathrm{~g}$ of potassium bromide slowly under constant stirring for $4 \mathrm{~h}$. This bottle was stored for another $16 \mathrm{~h}$ at NTP. After soaking, the residual/bromine pretreated solid was vacuum filtered, dried at $75{ }^{\circ} \mathrm{C}$ in an air environment for two days. All pretreated chitosan sorbents were ground and sieved to 150 mesh size.

\subsection{Experimental apparatus and procedures}

The stock solution of lead (II) ions was prepared by dissolving an accurate quantity of $\mathrm{Pb}\left(\mathrm{NO}_{3}\right)_{2}$ in deionized water. And other lead (II) solutions (varying between 5 and $50 \mathrm{mg} / \mathrm{L}$ ) were prepared from stock solution by dilution and $\mathrm{pH}$ was adjusted by $0 \cdot 1 \mathrm{M} \mathrm{HNO}_{3}$ and/or $0 \cdot 1 \mathrm{M} \mathrm{NaOH}$ solutions. The fresh dilutions were made for each adsorption experiment.

\subsection{Batch adsorption studies}

All batch experiments were done in a beaker with $50 \mathrm{ml}$ lead sample solution kept on a magnetic shaker at $250 \mathrm{rpm}$. The effect of $\mathrm{pH}$ on lead (II) adsorption was determined by equilibrating adsorption mixture with dried sorbents and $10 \mathrm{ppm}$ of $50 \mathrm{ppm}$ stock lead concentration at a range of $\mathrm{pH} 1-7$. The effect of $20 \%$ iodine/bromine pretreated sorbent was studied by changing dose from $2.5-50 \mathrm{~g} / \mathrm{L}$. The optimum $\mathrm{pH}$ was then determined as $5-5 \cdot 5$, and adsorption studies were done at $\mathrm{pH}$ 5. At equilibrium, lead (II) adsorption attains its maximum removal from water, then resultant solutions were centrifuged at $4000 \mathrm{rpm}$ for a while and supernatants were subjected to quantitative analysis by atomic absorption spectrophotometer. The adsorption studies were evaluated at a temperature range of $25-40{ }^{\circ} \mathrm{C}$ by applying Lagergren first order and pseudo-second-order kinetic models. 


\subsection{Analytical methods}

Lead (II) ions concentrations were determined by using an atomic absorption spectrophotometer (Hitachi, Japan) with an air-acetylene flame. Deuterium background correction was used and the spectral slit width was $1.3 \mathrm{~nm}$. About $50 \mathrm{ml}$ of particular lead (II) containing solution was taken in shaking bottles and known weight of pretreated adsorbents were added to them followed by shaking on a rotary shaker with a stirring speed of $200 \mathrm{rpm}$ for $24 \mathrm{~h}$ to attain its equilibrium. Subsequently, all solutions were filtered through Whatman filter paper No. 42 and corresponding filtrates were analysed for residual lead concentration by atomic absorption spectrophotometer (GBC, 932-AA., Australia).

\section{Results and discussion}

\subsection{BET surface area and pore structure parameters of bromine pretreated chitosan}

Textural characteristics of $30 \%$ bromine pretreated chitosan were determined by nitrogen $\left(\mathrm{N}_{2}\right)$ adsorption-desorption study at $77 \mathrm{~K}$ on adsorbent surface area and porosimeter (ASAP 2020, M.I). Adsorption isotherms studies were done to calculate average pore volume diameter of bromine pretreated chitosan which was found to be four times of average pore volume over BET surface area. BET surface areas and pore structure parameters of bromine pretreated chitosan sorbent are given in table 1. BET surface areas and pore volumes of both sorbents were found actually decreased by pretreatment with bromine that is due to blockage of internal porosity by bromine (in $\mathrm{KBr}$ form) insertion in chitosan inventive skeleton (figure 1). Further, blocked pores may become micropores and ultimately decrease specific surface area as well as total pore volume of pretreated chitosan sorbent (Gérente et al 2007). Average pore size was found to be increased after pretreatment of chitosan with bromine.

Table 1. BET surface area and pore structure parameters of bromine pretreated chitosan.

\begin{tabular}{lcccc}
\hline $\begin{array}{l}\text { S1. } \\
\text { no. }\end{array}$ & Adsorbents & $\begin{array}{c}\text { BET surface } \\
\text { area } \\
\left(\mathrm{m}^{2} / \mathrm{g}\right)\end{array}$ & $\begin{array}{c}\text { Total pore } \\
\text { volume } \\
\left(\mathrm{cm}^{3} / \mathrm{g}\right)\end{array}$ & $\begin{array}{c}\text { Average pore } \\
\text { diameter } \\
(\mathrm{nm})\end{array}$ \\
\hline 1. & Chitosan (pure) & $2 \cdot 88$ & 0.014 & 10 \\
2. & Chitosan-Br- $A$ & 0.72 & 0.002 & 14 \\
3. & Chitosan-Br- $B$ & 0.46 & 0.002 & 18 \\
4. & Chitosan-Br- $C$ & 0.41 & 0.002 & 19 \\
5. & Chitosan-Br- $D$ & 0.36 & 0.002 & 21 \\
\hline
\end{tabular}

Chitosan was used as it is in the first case; while the bromine $(\mathrm{Br})$ pre-treatment was done using different proportions (in weight by volume) indicated as $A=5 \%, B=10 \%, C=20 \%$ and $D=30 \%$. The surface properties of each material was measured in triplicates and the average values are presented in the table.
Generally, pure physisorption dominates sorbent's adsorptive capacity and runs parallel with its specific surface area (Atia et al 2003). In fact BET surface areas of bromine pretreated chitosan is rather smaller than normal activated carbon, hence, physisorption of lead is limited. Nevertheless, pretreatment of chitosan surface enhances chemisorptions over physisorption due to creation of new active sites which binds lead cations on linkages of $30 \%$ bromine pretreated sorbent.

\subsection{Elemental analysis of bromine pretreated chitosan}

Elemental analysis data estimates the density of active sites created in pretreated chitosan sorbent. Carbon, hydrogen and nitrogen absolute weight (wt \%) were calculated by an elemental analyser (EL-2, Vario) and bromine relative weight (rwt \%) were determined by X-ray fluorescence technique using fluorimeter. Pretreated chitosan were somewhat lower in composition $\mathrm{C} \%, \mathrm{H} \%$ \& $\mathrm{N} \%$ elements than the pure chitosan and experimental values of iodine and bromine as provided in table 2 .

\subsection{Differential thermal gravimetric analysis (DTA)}

Thermal stability of pure and bromine pretreated chitosan were done to establish upper temperature limit for adsorbents using thermal gravimetric analysis (DTA Mettler Toledo-851) as shown in figures 2 and 3. About $25 \mathrm{mg}$ of pretreated adsorbent was taken for study of DTA under $\mathrm{N}_{2}$ gas flow at $50 \mathrm{~mL} / \mathrm{min}$. The temperature involved in heating pretreated sorbent was at a rate of $10{ }^{\circ} \mathrm{C} / \mathrm{min}$ from $25-100{ }^{\circ} \mathrm{C}$ (trapped for half an hour at this temperature), then heated further at the rate of $10^{\circ} \mathrm{C} / \mathrm{min}$ up to $500{ }^{\circ} \mathrm{C}$ for $24 \mathrm{~h}$. The data showed two peaks/ differential thermogravimetry (DTA) curve for the weight loss rate corresponding to two desorption processes in different temperature ranges. The first DTG curve/peak is due to physically adsorbed water desorption which occurred in the temperature range of $50-100{ }^{\circ} \mathrm{C}$. The second DTA curve exhibited a rapid weight loss at $200-225^{\circ} \mathrm{C}$ reaching a maximum at $313.3{ }^{\circ} \mathrm{C}$ for chitosan, similarly at $317.4{ }^{\circ} \mathrm{C}$ and $460 \cdot 3{ }^{\circ} \mathrm{C}$ for chitosan pretreated bromine. Pretreatment of bromine in chitosan alters its intrinsic inter as well as extra molecular hydrogen bonding besides provide some superfluous active sites in sorbent for lead (II) removal from water.

\subsection{FTIR analysis of bromine pretreated chitosan sorbent}

Fourier-transform infra red (Nicolet Magna IR 550-FTIR) technique of potassium bromide pressed pellet were used for chitosan before and after pretreatment to study structural changes besides surface chemistry as shown in figures 4 and 5. FTIR spectra were recorded in 400-4000 $\mathrm{cm}^{-1}$ range at a resolution of $4 \mathrm{~cm}^{-1}$ and 64 scans were accumulated which exhibits significant IR band changes 


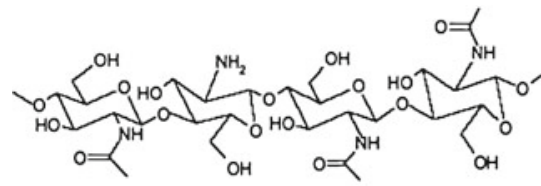

Structure of Chitin

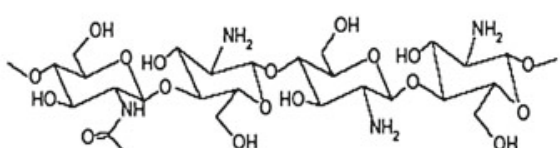

Structure of Chitosan

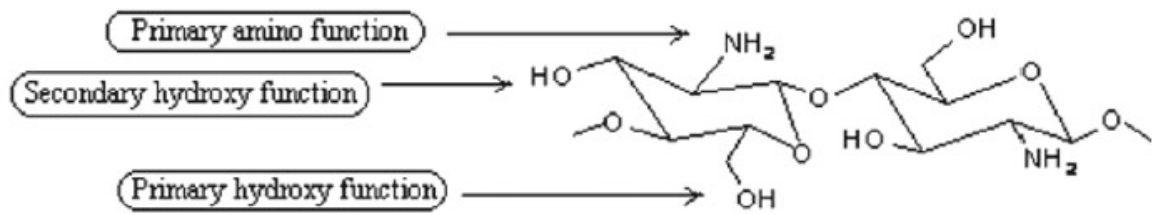

Figure 1. Molecular structures of chitin and chitosan indicating positions of functional groups.

Table 2. Element analysis of bromine pretreated chitosan sorbents.

\begin{tabular}{|c|c|c|c|c|c|}
\hline \multirow{2}{*}{$\begin{array}{l}\text { S1. } \\
\text { no. }\end{array}$} & \multirow[b]{2}{*}{ Adsorbents } & \multicolumn{3}{|c|}{ Element (wt/\%) } & \multirow{2}{*}{$\frac{\text { Element (rwt \%) }}{\mathrm{Br}}$} \\
\hline & & $\mathrm{C}$ & $\mathrm{H}$ & $\mathrm{N}$ & \\
\hline 1. & Chitosan (pure) & $38 \cdot 73$ & $7 \cdot 78$ & $6 \cdot 99$ & 0 \\
\hline 2. & Chitosan-Br- $A$ & $36 \cdot 20$ & $7 \cdot 12$ & $6 \cdot 59$ & $4 \cdot 81$ \\
\hline 3. & Chitosan-Br- $B$ & $29 \cdot 38$ & $6 \cdot 31$ & $5 \cdot 37$ & $9 \cdot 02$ \\
\hline 4. & Chitosan-Br- $C$ & $23 \cdot 95$ & 5.99 & $4 \cdot 39$ & $18 \cdot 37$ \\
\hline 5. & Chitosan-Br- $D$ & $21 \cdot 55$ & $4 \cdot 88$ & $4 \cdot 39$ & $28 \cdot 87$ \\
\hline
\end{tabular}

The chitosan purchased was used as it is in the first case; while bromine (Br) pre-treatment was done using different proportions (in weight by volume) indicated as $A=5 \%, B=10 \%, C=20 \%$ and $D=30 \%$. The surface properties of each material was measured in triplicates and the average values are presented in the table.

since each specific adsorbent's chemical bonding owes unique energy absorption pattern. Pure chitosan showed characteristics absorption band viz. at $3436 \mathrm{~cm}^{-1}$ for $\mathrm{O}-\mathrm{H}$ and/or $\mathrm{N}-\mathrm{H}$ stretching, $2932 \mathrm{~cm}^{-1}$ for $\mathrm{C}-\mathrm{H}$ stretching, $1652 \mathrm{~cm}^{-1}$ for $\mathrm{C}=\mathrm{O}$ stretching in amide, $1580 \mathrm{~cm}^{-1}$ for $\mathrm{N}-\mathrm{H}$ bending in amide, $1149 \mathrm{~cm}^{-1}$ for bridge-O-stretching and $1090 \mathrm{~cm}^{-1}$ for $\mathrm{C}-\mathrm{O}$ stretching (Cardenas and Patricia Miranda 2004).

Nonetheless, 30\% bromine pretreated chitosan showed wide absorption band at $3395 \mathrm{~cm}^{-1}$ (little shifted to lower wavenumber) due to stretched vibration of $-\mathrm{NH}_{2}$ and $-\mathrm{OH}$ groups. Another smaller band at $1092 \mathrm{~cm}^{-1}$ shifted to higher wavenumber which is due to $\mathrm{C}-\mathrm{O}$ stretching indicates binding of iodine at linkages like $-\mathrm{NH}_{2},-\mathrm{OH}$ and $\mathrm{C}-\mathrm{O}$ of chitosan skeleton. Further, significant decrease in absorption band of $\mathrm{N}-\mathrm{H}$ stretching at $3100-3500 \mathrm{~cm}^{-1}$ and $\mathrm{N}-\mathrm{H}$ bending at $1400-1660 \mathrm{~cm}^{-1}$ as pretreatment in chitosan surface modify all its skeletal bonds associated with amino linkages, indicated main adsorption site for bromine and subsequently lead too, after pretreatment. Accordingly new IR band at $2876 \mathrm{~cm}^{-1}$ arises due to bromine in pretreated chitosan which closely relates to the phenomenon of $\mathrm{N}-\mathrm{H}$ bending; $\mathrm{C}-\mathrm{N}$ stretching and $\mathrm{N}-\mathrm{H}$ rocking vibrations play signi-

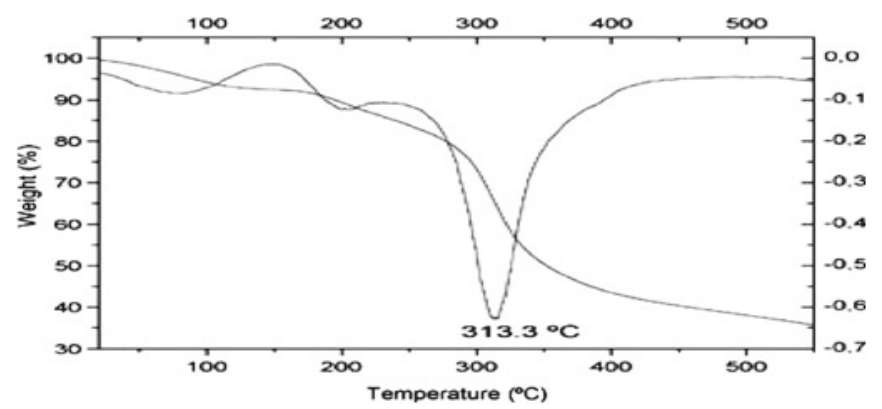

Figure 2. DTA thermogram of pure chitosan.

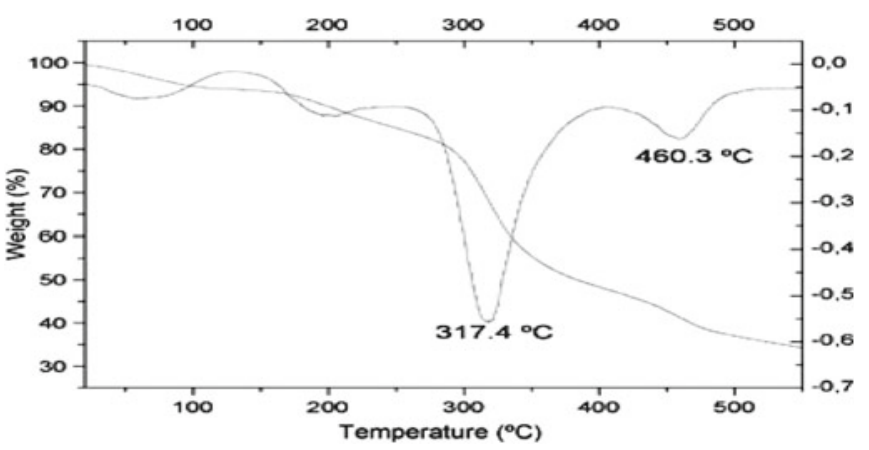

Figure 3. DTA thermogram of $30 \%$ bromine pretreated chitosan.

ficant role in lead removal. Another major IR band changes in bromine pretreated chitosan observed at $3174 \mathrm{~cm}^{-1}$ due to lead (II) adsorption which affects both $\mathrm{C}-\mathrm{H}$ vibrations and $\mathrm{O}-\mathrm{H}$ weak-broad stretching. Since lead is unlikely to be attached to a carbon of chitosan, results may, therefore, suggest that oxygen in hydroxyl group could also involve in lead adsorption which is less significant than amicable nitrogen of amino linkages.

\subsection{Performance of lead adsorption by bromine treated chitosan}

The key factor governing lead adsorption by $30 \%$ bromine pretreated chitosan sorbents includes $\mathrm{pH}, \%$ bromine loading, 


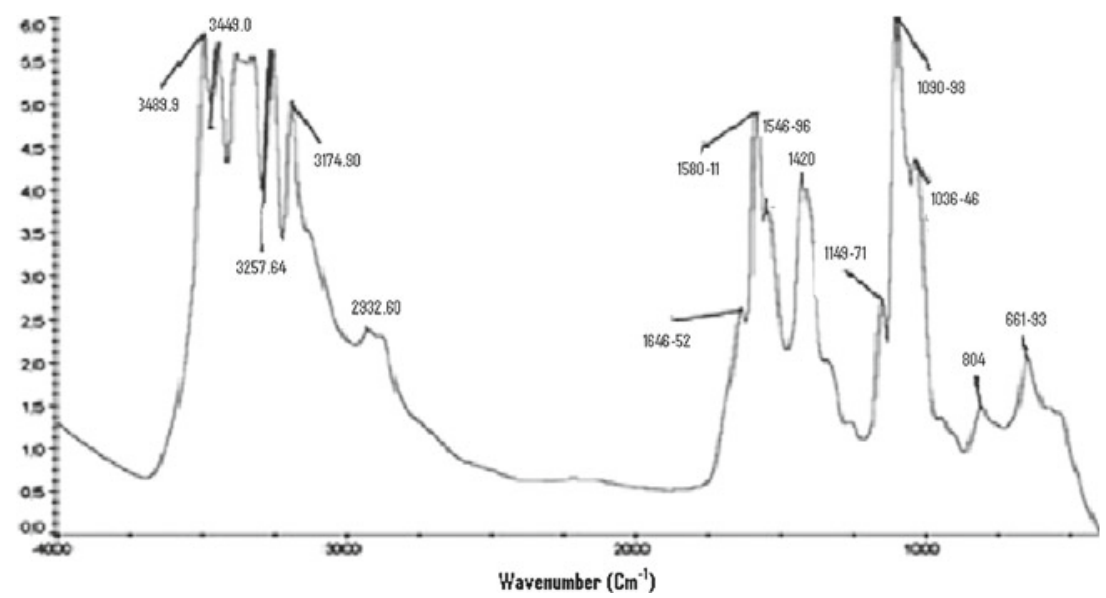

Figure 4. FTIR spectrum of pure chitosan.

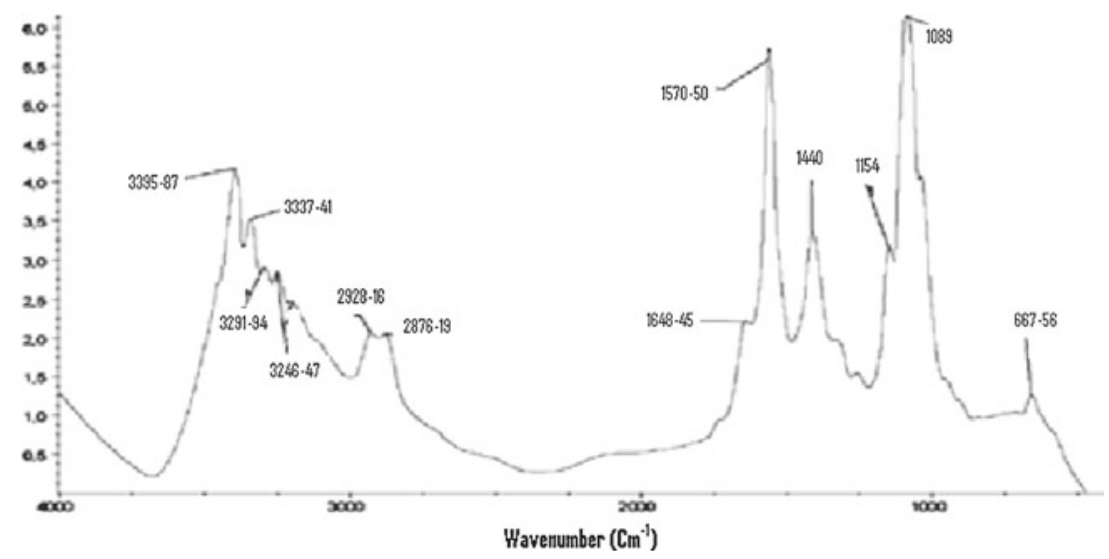

Figure 5. FTIR spectrum of $30 \%$ bromine pretreated chitosan.

sorbent dose, initial lead concentration, adsorption kinetics and temperature.

3.5a Effect of $p H$ : The $\mathrm{pH}$ has a very significant effect in determining lead (II) sorption on 30\% bromine pretreated chitosan from water. Since $\mathrm{pH}$ of adsorption solutions affects surface charges of pretreated chiotosan skeleton at specific functional groups such as hydroxyl and amino groups (Guibal 2004; Vilar et al 2005). Adsorption of lead (II) on $30 \%$ bromine pretreated chitosan as a function of $\mathrm{pH}$ is shown in figure 6 which indicated the maximum \% lead removal achieved at a range of $\mathrm{pH} 5-5 \cdot 5$, with the efficiency of $Q_{\mathrm{m}}=0.8 \mathrm{mg} / \mathrm{g}$ of sorbent as calculated according to following equation

$$
Q_{\mathrm{m}}=\left(C_{\mathrm{i}}-C_{\mathrm{eq}}\right) V / m,
$$

where $V$ is volume of sample solution $(\mathrm{ml}), m$ the mass of $30 \%$ bromine pretreated chitosan sorbent $(\mathrm{g}), C_{\mathrm{i}}$ and $C_{\text {eq }}$ are the initial and equilibrium/final concentration of lead in solution $(\mathrm{mg} / \mathrm{l})$, respectively. 3.5b Effect of bromine load on sorbent dose: The optimum breakthrough ratio of bromine loaded in pretreated chitosan sorbent was found to be $30 \%(\mathrm{w} / \mathrm{v})$ of chitosan. Amongst pretreated sorbents used for lead removal, 30\% bromine $(\mathrm{w} / \mathrm{v})$ pretreated chitosan exhibited excellent lead adsorption capacity with an optimized sorbent dose of $20 \mathrm{~g} / \mathrm{L}$ as shown in figure 7 .

$3.5 \mathrm{c}$ Effect of $30 \%(w / v)$ bromine pretreated chitosan dose: The effect of $30 \%$ bromine pretreated chitosan on adsorption capacity of lead (II) was studied by varying $30 \%$ bromine pretreated adsorbent dose from 0.5 to $50 \mathrm{~g} / \mathrm{L}$ as shown in figure 8 . The maximum adsorption capacity of $0.81 \mathrm{mg} / \mathrm{g}$ were reached in sorbent's dose range of 15-20 g/L that further decreases with increasing sorbent dose as may be due to specific surface adsorption phenomenon. At low sorbent dose all the active sites of sorbent get utilized completely and effectively resulting in high lead adsorption capacity, on the contrary increasing sorbent dose while maintaining lead concentration steady escorts to surplus of adsorbent sites (Hirayama et al 1998; Meghat Hanafiah et al 2007). 


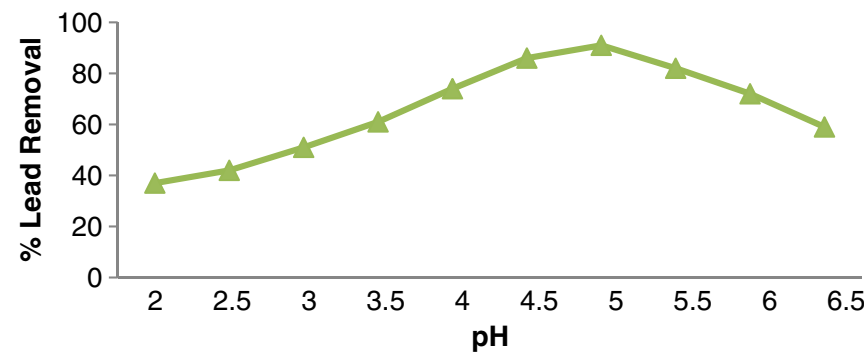

Figure 6. Effect of $\mathrm{pH}$ on lead adsorption (40 ppm lead concentration, $20 \mathrm{~g} / \mathrm{L}$ sorbent and contact time, $6 \mathrm{~h}$ ). 3.5d Effect of initial lead concentration: The amount of lead (II) distribution amongst sorbent and solution at equilibrium is vital in determining maximum lead adsorption capacity of adsorbent. Hence, the effect of initial lead (II) concentration on sorption capacity of $30 \%$ bromine pretreated chitosan was investigated at an optimized $\mathrm{pH}$ at 5.0 as shown in figure 9. The lead (II) adsorption increased much quickly with increasing initial metal concentration from $10-50 \mathrm{mg} / \mathrm{L}$. A higher initial lead concentration provides driving force to overcome all mass transfer resistances between solution and sorbent surface, consequently lead (II) adsorption capacity increased. Besides, the number of collisions between lead (II)

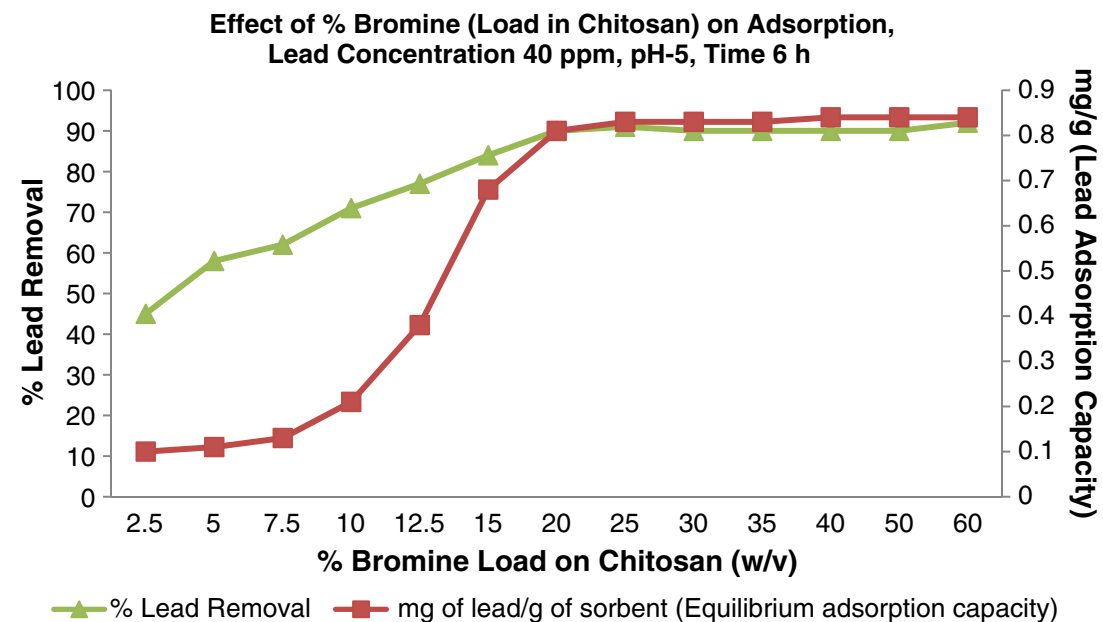

Figure 7. Effect of \% bromine (loaded in chitosan) on adsorption.

Effect of 30\% Bromine Pretreated Chitosan Sorbent Dose on Lead Adsorption, pH-5, Lead Concentration $=40$ ppm, Time $6 \mathrm{~h}$

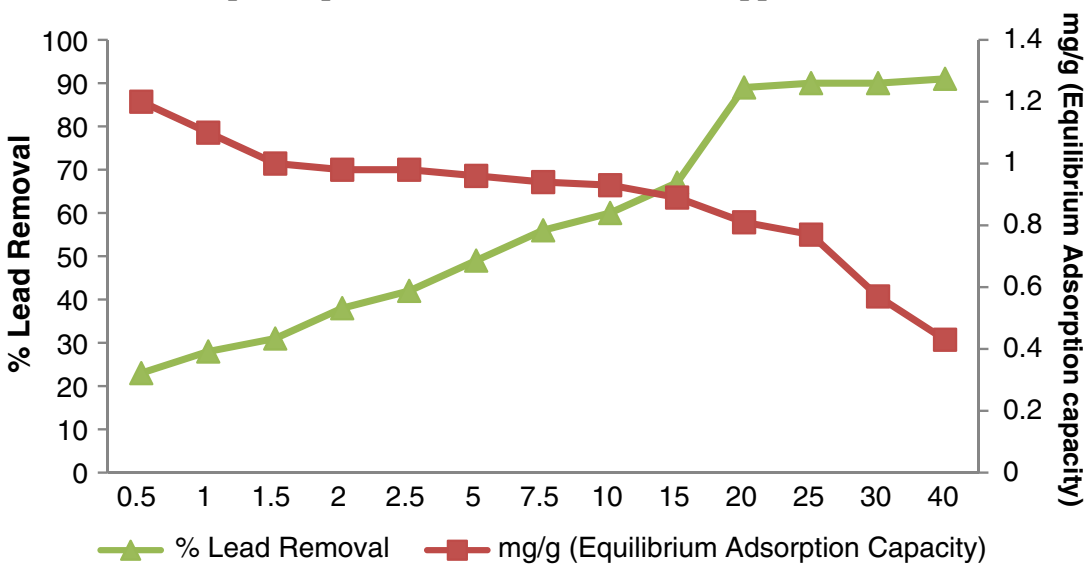

Figure 8. Effect of $30 \%(\mathrm{w} / \mathrm{v})$ bromine pretreated chitosan dose. 


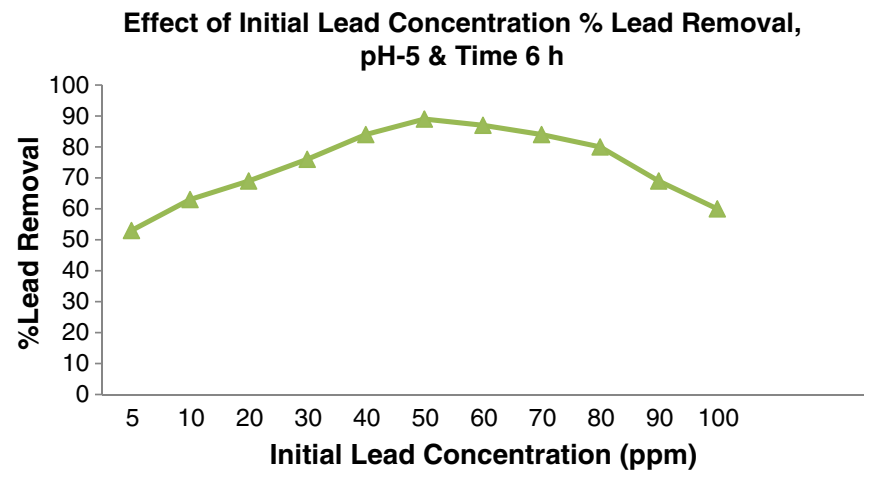

Figure 9. Effect of initial lead concentration on adsorption of lead.

ions and bromine pretreated sorbent increases parallelly with initial lead concentration (Jin and Bai 2002; Aksu and Tezer 2005; Trimukhe and Varma 2008). Moreover, lead (II) sorption rate decreases with increasing initial concentration from $50-100 \mathrm{mg} / \mathrm{L}$ which is due to the saturation of active sorption sites available for lead cations on bromine pretreated chitosan's surface.

3.5e Effect of temperature: The temperature effect studies for lead removal were done at varied ranges from 20$50{ }^{\circ} \mathrm{C}$ with bromine pretreated chitosan. Adsorption experimental data exhibited obviously reduced capacity i.e. \% lead adsorption decreases as temperature increases. At $20{ }^{\circ} \mathrm{C}$ initial value $\eta$ of lead breakthrough reached 0.35 , but it increased rapidly with time and there is a slow increase of $\eta$ at $50{ }^{\circ} \mathrm{C}$. The increase in lead removal efficiency is observed at elevated temperature, since lead adsorption is a chemical/chemisorption phenomenon and requires activation energy, so it proceeds in limiting rate which further enhances with rise in temperature (Schmuhl et al 2001).

\subsection{Possible lead removal mechanism}

The results of analysis data support chemical interaction of $\mathrm{KBr}$ with chitosan to produce $\mathrm{Br}_{2}$ and some unreacted bromides exist in adsorption media. Amine group of chitosan via $\mathrm{N}$-atom reacts with $\mathrm{Br}_{2}$ as well as with some unreacted bromides and subsequently lead cations react with these active sites (such as $\mathrm{Br}_{2}$ and some un-reacted bromides) yielding lead adsorption (Zhang et al 2009). The relatively higher lead removal efficiency by addition of sulfuric acid in pretreatment process of adsorbents was also observed. Generally, bromine pretreated chitosan demonstrated higher lead capture efficiency than that of sulfuric acid pretreated chitosan. Among all the sorbents used, 30\% bromine loads on chitosan shows the best lead removal capacity of 85-90\% in $6 \mathrm{~h}$. The synthetic optimization of $30 \%$ bromine loading on pretreated chitosan and desorption/regeneration of sorbent is to be further evaluated for getting a type of promising and low-cost adsorption technique. The following chemical interactions are proposed to account for chemisorptions of lead (II) on $30 \%$ bromine pretreated chitosan surface as:

$$
\begin{aligned}
& R-\mathrm{NH}_{2}+\mathrm{H}^{+} \leftrightarrow R-\mathrm{NH}_{3}^{+}, \\
& R-\mathrm{NH}_{3}^{+}+\mathrm{Br}^{-} \rightarrow R-\mathrm{NH}_{3}^{+} \cdot \mathrm{Br}^{-}, \\
& R-\mathrm{NH}_{3}^{+} \cdot \mathrm{Br}^{-}+\mathrm{Pb}^{2+} \rightarrow R-\mathrm{NH}_{2}^{+} \mathrm{Br}^{-}\left(\mathrm{Pb}^{2+}\right)_{1 / 2},
\end{aligned}
$$

$$
R-\mathrm{NH}_{3}^{+} \mathrm{Br}^{-}+\mathrm{Pb}^{2+} \rightarrow R-\mathrm{NH}_{2} \mathrm{~Pb}^{2+}+\mathrm{H}^{+} \mathrm{Br}^{-},
$$

where $R$ represents organic components except $-\mathrm{NH}_{2}$ in chitosan. At lower/acidic $\mathrm{pH}$, more amino groups of chitosan are protonated besides bind bromide resulting in higher capture of lead cations (Dai et al 2010). However, at basic $\mathrm{pH}, \mathrm{OH}^{-}$ions may be adsorbed on active surface of chitosan through inter-hydrogen bonding and contributes to less capture of lead cations as

$$
R-\mathrm{NH}_{2}+\mathrm{OH}^{-} \rightarrow R-\mathrm{NH}_{2} \cdots \mathrm{OH}^{-} .
$$

Further, the sorption dynamic followed pseudo-second order equation, as well adsorption performance cannot be simply explained through an electrostatic interaction, but complexation, ion exchange factors are also significant (Jin and Bai 2002). Rather lead adsorption process was complex, both boundary of liquid film (surface adsorption phenomen) and intra-particle diffusion contributed to ratedetermining step. Thermodynamic study and kinetic analysis reveals spontaneous and rapid chemisorptions process with an increased randomness of lead (II) sorption onto $30 \%$ bromide pretreated chitosan, which showed possibility of a practicable operation in packed columns with pretreated sorbent.

\subsection{Lead (II) adsorption efficiency and capacity of $30 \%$ bromine pretreated chitosan}

The adsorption kinetic study is a vital physiochemical parameter to evaluate the potential and efficiency of sorbent. Hence, adsorption kinetic study was performed with different lead concentrations for sorption onto modified chitosan sorbent at an optimum $\mathrm{pH}$ of 5 and stirring speed of $200 \mathrm{rpm}$. At initial lead concentrations of 10, 20, 30, 40, 50 and $60 \mathrm{mg} / \mathrm{L}(\mathrm{ppm})$, amount of metal adsorbed were $8.5 \mathrm{mg} / \mathrm{L}, 17.1 \mathrm{mg} / \mathrm{L}$, $26.1 \mathrm{mg} / \mathrm{L}, 35.4 \mathrm{mg} / \mathrm{L}, 45.1 \mathrm{mg} / \mathrm{L}$ and $54.1 \mathrm{mg} / \mathrm{L}$, respectively. The lead (II) adsorption onto bromine pretreated chitosan is plotted as a function of time at various initial lead concentrations. Figure 10 showed increased lead (II) concentration so does the time taken before equilibrium is attained. At lower lead concentrations, lesser adsorption is found than at higher concentrations. The adsorption kinetic results showed that sorption is a rapid process, and the equilibrium is 


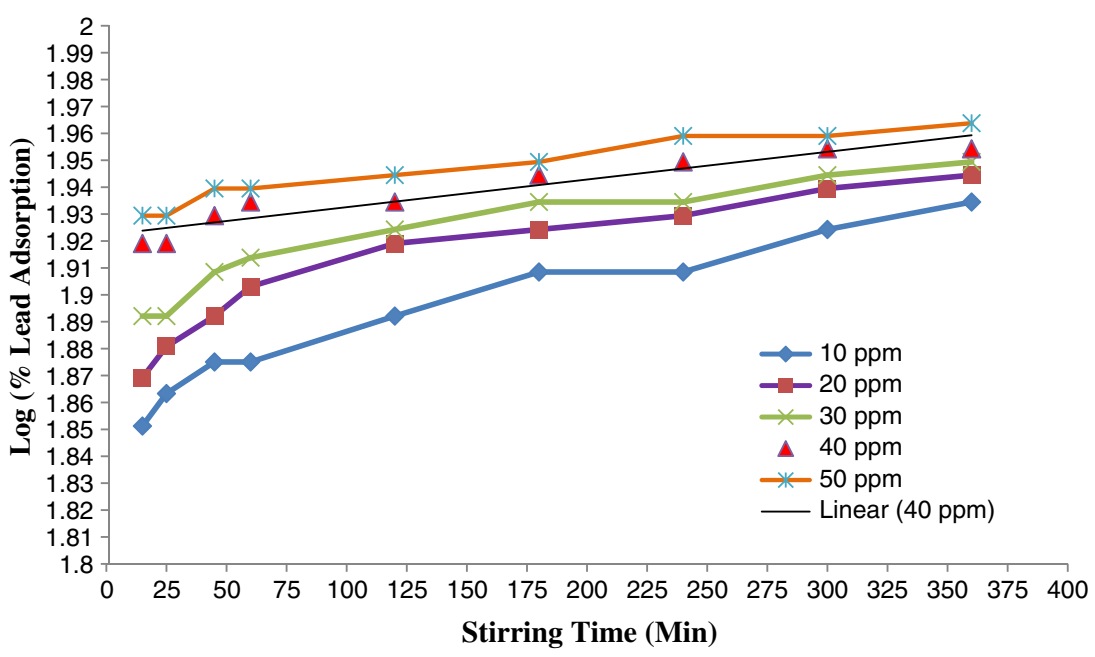

Figure 10. Adsorption kinetics of lead (II) on $30 \%$ bromine pretreated chitosan at different initial concentrations $\left[\mathrm{Pb}^{+}\right]$of $10,20,30,40$ and $50 \mathrm{mg} / \mathrm{L}(\mathrm{ppm})$, sorbent dose, $20 \mathrm{~g} / \mathrm{L}, \mathrm{pH} 5$, stirring speed $=200 \mathrm{rpm}$ and temperature $=27^{\circ} \mathrm{C}$.

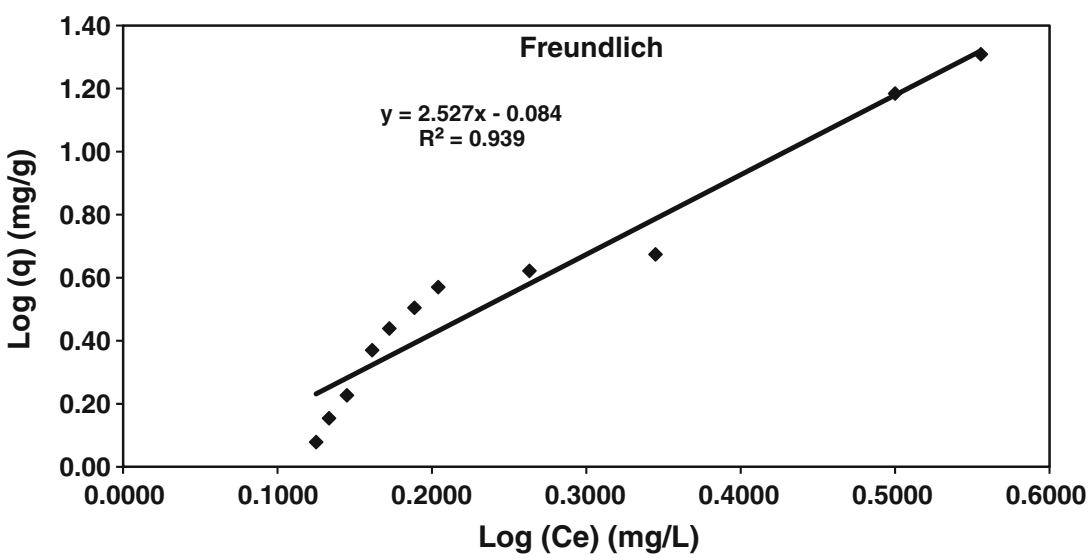

Figure 11. Freundlich isotherm for lead adsorption by $30 \%$ bromine iodine pretreated chitosan.

reached at 15 to $20 \mathrm{~min}$ for all lead (II) concentrations. These results clearly indicate that $30 \%$ bromine pretreated chitosan can potentially remove lead cations from aqueous solution. The amount of lead (II) adsorbed on sorbent is explained on the basis of ionic radii lead cation $1.21 \AA$ and its less hydration energy. The distribution coefficient is the ratio of lead between $30 \%$ bromine pretreated chitosan and aqueous phase which is observed to be more than 1.0 indicated high sorption efficiency. Further this distribution coefficient is dependent on the initial metal ion concentrations and enhances parallelly.

\subsection{Adsorption isotherms study}

The lead adsorption onto 30\% bromine pretreated chitosan at room temperature has been studied with lead sample concentration which varied from $5-50 \mathrm{ppm}$ at $\mathrm{pH}=5$ for $6 \mathrm{~h}$ of contact time. The adsorption experimental data matched in accordance with Langmuir and Freundlich models which are widely used to describe the equilibrium of lead adsorption (Asandei et al 2009). Freundlich adsorption model is appropriate to describe lead adsorption onto $30 \%$ bromine pretreated chitosan and linear Freundlich isotherm is presented in figure 11 .

\subsection{Desorption/regeneration study}

Chemisorptions of lead onto $30 \%$ bromine pretreated chitosan were confirmed by FTIR and isothermal study and found to be low in acidic medium, due to protonation of all amino linkages of chitosan. Low acidic $\mathrm{pH}$ of adsorption medium induces an electrostatic repulsion to lead cations by competent $\mathrm{H}^{+}$for sorption onto active sites of chitosan (Wong et al 2003; Asandei et al 2009). However, this protonation of amino groups diminished as $\mathrm{pH}$ of sorption medium increased due to less competition with $\mathrm{H}^{+}$and consequently 
uptake of lead were increased at $\mathrm{pH}$ range 5-5.5. Further, adsorbate surface is sufficiently negatively charged at $\mathrm{pH} 5$ which strongly attracts lead by electrostatic force which is in accordance with lead speciation diagram (Lead Speciation Diagram 2009). Over this pH domain, lead occurs predominantly as divalent free cation, which gets involved in chemical processes during sorption onto sorbent.

Besides, desorption study was performed over whole $\mathrm{pH}$ range and maximum desorption of lead by bromine pretreated sorbent were observed at $\mathrm{pH} 3$ due to main electrostatic binding of lead to amino groups of chitosan (Qin et al 2006). Further, lead removal efficiency was lower at $\mathrm{pH} 3$ than at $\mathrm{pH} 5$ presumably due to instability of chitosan at such extremely low $\mathrm{pH}$. However, at basic conditions $(\mathrm{pH}>$ 7) chemisorptions of lead decreases, since chitosan surface undergoes deprotonation results in less sorption. The lead desorption efficiency experiments were done with $0.1 \mathrm{M}$ $\mathrm{HNO}_{3}$ solutions. About $1 \mathrm{~g}$ of bromine pretreated adsorbent were shaken with $50 \mathrm{ml}$ of $40 \mathrm{ppm}$ lead sample concentration into $100 \mathrm{~mL}$ of a $\mathrm{HNO}_{3}$ solution on thermostatic shaking machine and the desorption was allowed for a time period up to $24 \mathrm{~h}$. The desorption efficiency (DE) was determined by following equation:

$$
\mathrm{DE}=(C / q \times V / m) \times 100 \%,
$$

where, $C(\mathrm{mg} / \mathrm{L})$ is lead (II) sample concentration taken for desorption study, $V$ (litre) the volume of desorption solution, $q(\mathrm{mg} / \mathrm{g})$ the amount of lead (II) ions adsorbed on the bromine pretreated chitosan before desorption experiment and $m(g)$ is the mass of the bromine pretreated chitosan used in the desorption experiments. Regeneration of 30\% bromine pretreated chiotsan was done after lead adsorption at different initial $\mathrm{pH}$ values. The regenerated/desorbed sorbent were reused and comparative lead adsorption study of reused $30 \%$ bromine pretreated chitosan were done in four cycles and found overall $10-15 \%$ decrease in lead (II) removal efficiency as mentioned in table 3 .

\section{Conclusions}

Bromine pretreated chitosan was found to be promising adsorbent for lead (II) removal from water. The major experimental observations are summarized below:

(I) 30\% Bromine pretreated chitosan showed 85-90\% lead (II) removal capacity at ambient conditions.

(II) The regeneration ability of $30 \%$ bromine pretreated chitosan was tested in four sequential cycles which exhibited an overall 10-15\% loss of lead adsorption capacity.

(III) Lead adsorption capacity of $30 \%$ bromine pretreated chitosan increases from acid to neutral medium and maximum at $\mathrm{pH}=5$ to 5.5 in contact time of $6 \mathrm{~h}$.

(IV) Maximum lead (II) removal efficiency of $85-90 \%$ was achieved at an optimum dose of $20 \mathrm{~g} / \mathrm{L}$ of $30 \%$ bromine pretreated chitosan, indicating benign and cost-effective adsorption technique.

(V) FTIR showed binding of lead (II) onto nitrogen of amine and $-\mathrm{OH}$ groups of $30 \%$ bromine pretreated chitosan also contributes through a nonspecific electrostatic interaction although less significant compared to other active sites of sorbent.

(VI) Langmuir and Freundlich isotherm models applied for mathematical adsorption data were found to be very well fitted to Freundlich with a maximum adsorption capacity of $1.755 \mathrm{~g}$ lead per $\mathrm{kg}$ of $30 \%$ bromine pretreated chitosan.

Table 3. Comparative lead adsorption by reused $30 \%$ bromine pretreated chitosan

\begin{tabular}{|c|c|c|c|c|c|c|c|}
\hline \multicolumn{2}{|c|}{ I Adsorption cycle } & \multicolumn{2}{|c|}{ II Adsorption cycle } & \multicolumn{2}{|c|}{ III Adsorption cycle } & \multicolumn{2}{|c|}{ IV Adsorption cycle } \\
\hline $\mathrm{pH}$ & $\begin{array}{c}\% \text { Lead } \\
\text { (II) removal }\end{array}$ & $\mathrm{pH}$ & $\begin{array}{c}\% \text { Lead } \\
\text { (II) removal }\end{array}$ & $\mathrm{pH}$ & $\begin{array}{c}\% \text { Lead } \\
\text { (II) removal }\end{array}$ & $\mathrm{pH}$ & $\begin{array}{c}\% \text { Lead } \\
\text { (II) removal }\end{array}$ \\
\hline $2 \cdot 0$ & 28 & $2 \cdot 0$ & 23 & $2 \cdot 0$ & 19 & $2 \cdot 0$ & 16 \\
\hline $2 \cdot 5$ & 34 & $2 \cdot 5$ & 29 & $2 \cdot 5$ & 26 & $2 \cdot 5$ & 23 \\
\hline $3 \cdot 0$ & 51 & $3 \cdot 0$ & 46 & $3 \cdot 0$ & 44 & $3 \cdot 0$ & 43 \\
\hline $3 \cdot 5$ & 61 & $3 \cdot 5$ & 53 & $3 \cdot 5$ & 49 & $3 \cdot 5$ & 48 \\
\hline $4 \cdot 0$ & 74 & $4 \cdot 0$ & 65 & $4 \cdot 0$ & 52 & $4 \cdot 0$ & 54 \\
\hline $4 \cdot 5$ & 86 & $4 \cdot 5$ & 74 & $4 \cdot 5$ & 69 & $4 \cdot 5$ & 59 \\
\hline $5 \cdot 0$ & 91 & $5 \cdot 0$ & 83 & $5 \cdot 0$ & 76 & $5 \cdot 0$ & 68 \\
\hline $5 \cdot 5$ & 82 & $5 \cdot 5$ & 75 & $5 \cdot 5$ & 71 & $5 \cdot 5$ & 62 \\
\hline $6 \cdot 0$ & 72 & $6 \cdot 0$ & 70 & $6 \cdot 0$ & 66 & $6 \cdot 0$ & 60 \\
\hline $6 \cdot 5$ & 59 & $6 \cdot 5$ & 56 & $6 \cdot 5$ & 51 & $6 \cdot 5$ & 48 \\
\hline $7 \cdot 0$ & 46 & $7 \cdot 0$ & 41 & $7 \cdot 0$ & 38 & $7 \cdot 0$ & 34 \\
\hline $7 \cdot 5$ & 38 & $7 \cdot 5$ & 33 & $7 \cdot 5$ & 30 & $7 \cdot 5$ & 28 \\
\hline 8.0 & 33 & 8.0 & 30 & 8.0 & 27 & 8.0 & 24 \\
\hline 8.5 & 29 & $8 \cdot 5$ & 24 & 8.5 & 22 & 8.5 & 19 \\
\hline 9.0 & 23 & $9 \cdot 0$ & 21 & $9 \cdot 0$ & 18 & 9.0 & 16 \\
\hline
\end{tabular}




\section{Acknowledgements}

The authors are thankful to Department of Chemistry, Rashtrasant Tukadoji Maharaj Nagpur University, Nagpur, Department of Biotechnology, Madhav Institute of Technology \& Science, Gwalior and Director, NEERI, Nagpur, India for providing necessary laboratory facilities and characterization studies needed for this research work.

\section{References}

Abo-Farha S, Abdela-A A Y, Ashour A and Garamon S 2009 J. Hazard. Mater. 169190

Aksu Z and Tezer S 2005 Process Biochem. 401347

Agency for Toxic Substances and Disease Registry (ATSDR) 2007 Toxicological profile for Lead (Atlanta, GA: U.S. Department of Health and Human Services, Public Health Service)

Arrascue M L, Garcia H M, Horna O and Guibal E 2003 Hydrometallurgy 71191

Asandei D, Bulgariu L and Bobu E 2009 Cellulose Chem. Technol. 43211

Atia A A, Donia A M, Abou-El-Enein S A and Yousif A M 2003 Sep. Purif. Technol. 33295

Babel S and Kurniavan T A 2003 J. Hazard. Mater. B97 219

Badawy N A, El-Bayaa A A, Abdel-Aal A Y and Garamon S E 2009 J. Hazard. Mater. 1661266

Bailey S E, Olin T J, Bricka M R and Adrian D D 1999 Water Res. 332469

Brunton L L, Goodman L S, Blumenthal D, Buxton I and Parker K L 2007 Principles of toxicology, in Goodman and Gilman's manual of pharmacology and therapeutics, 1st ed. (Nagpur, McGraw-Hill Professional) ISBN 0071443436, pp 1131

Bulgariu L, Bulgariu D, Malutan T and Macoveanu M 2009a Adsorption Sci. Technol. 27435

Bulgariu L, Robu B and Macoveanu M 2009b Rev. Chim. 60 1025

Cardenas G and Patricia Miranda S 2004 J. Chilean Chem. Soci. 49291

Cochrane E L, Lu S, Gibb S W and Villaescusa I 2006 J. Hazard. Mater. B137 198

Dai J, Yan H, Yang H and Cheng R 2010 Chem. Eng. J. 165240

Das Nilanjana, Karthika P, Vimala R and Vinodini V 2008 Nat. Prod. Radiance 7133

Dzul Erosa M S, Saucedo Medina T I, Navarro Mendoza R, Avila Rodriguez M and Guibal E 2001 Hydrometallurgy 61157

Fujiwara K, Ramesh A, Maki T, Hasegawa H and Ueda K 2007 J. Hazad. Mater. 14639

Gérente C, Lee V K C, Le Cloirec P and McKay G 2007 Crit. Rev. Environ. Sci. Technol. 3741

Gogate P R and Pandit A B 2004 Adv. Environ. Res. 8553
Goyer R A 1993 Environ. Health Perspect. 100177

Guibal E 2004 Sep. Purif. Technol. 3843

Guo X, Zhang S and Shan X 2008 J. Hazard. Mater. 151134

Hirayama M, Caseri W R and Super U W 1998 J. Colloid Interface Sci. 20167

Ho Y S, Wase D A J and Forster C F 1999 Water SA 22219

Horsfall M and Spiff A L 2005 Afr. J. Biotechnol. 4191

$\mathrm{Hu}$ H, Shih R, Rothenberg S and Schwartz B S 2007 Environ. Health Perspect. 115455

Igwe J C and Abia A A 2006 Afr. J. Biotechnol. 51167

Jin L and Bai R B 2002 Langmuir 189765

Karri S K, Saper R B and Kales S N 2008 Current Drug Safety 354

Kuribayashi H, Watanabe M, Sbibuya M and Suzuki K 1988 Selective separation process of radionuclide in liquid waste (Oak Ridge, USA: Pmt. DOE Model) 1169

Lead speciation diagram calculated using EpH-web http://www. crct.pbymtl.ca/ephweb.php, accessed at 15.01.2009

Londrigan P J, Silbergeld E K and Froisnes J R 1990 Am. J. Public Health 80907

Makkuni A, Bachas L G and Varma R S 2005 Clean Technol. Environ. Policy 787

Meghat Hanafiah M A K, Yahya M Z A, Zakaria H and Ibrahim S C 2007 J. Appl. Sci. 7489

Milot C, Guibal E, Roussy J and Clorec P L 1998 Miner. Process. Extract. Metall. Rev. 19293

Nadeem M, Mahmood A, Shahid S A, Shah S S, Khalid A M and McKay G 2006 J. Hazard. Mater. 138604

Nan Li, Bai R B and Liu C K 2005 Langmuir 2111780

Ng J C Y, Cheung W H and McKay G 2003 Chemosphere 521021

Pearce J M 2007 Eur. Neurol. 57118

Pokras M A and Kneeland M R 2008 Eco-Health 5379

Quin Y, Shi B and Liu G 2008 Indian J. Chem. Technol. 3464

Qin F, Wen B, Shan Y, Xie N, Liu T, Zhang S Z and Khan S U 2006 Environ. Pollution 144669

Rusten B, Kolkinn O and Ødegaard H 1997 Water Sci. Technol. 3571

Sankararamakrishnan N, Sharma A K and Sanghi R 2007 J. Hazard. Mater. 148353

Schmuhl R, Krieg H M and Keizer K 2001 Water SA 271

Trimukhe K D and Varma A J 2008 Carbohydr. Polym. 71698

Ucun H, Bayhan Y K, Kaya Y, Cakici A and Algur O F 2003 Desalination 154233

Vieira R S and Beppu M M 2006 Colloids Surf. A279 196

Vilar V J P, Botelho C M S and Boaventura R A R 2005 Process Biochem. 403267

Wang A Q 2008 Chitin chemistry, 1st ed. (Beijing, Science Press) pp 169-200 \& 557

Wang Jing-Song, Bao Zheng-Lei, Chen Si-Guang and Yang Jin-Hui 2011 J. Eng. Gas Turbines Power 1333

Wong Y C, Szeto Y S, Cheung W H and Mckay G 2003 Langmuir 197888

Zhang A, Xiang J, Sun L, Hu S, Li P, Shi J, Fu P and Su S 2009 Ind. Eng. Chem. Res. 484980 